\title{
ALLELOPATHIC ACTIVITY OF ALGAL BLOOMS AGAINST SOME PLANT PATHOGENIC FUNGI IN EGYPT
}

\author{
Fekry M. Ghazal"; Mohamed A. Deyab ${ }^{* *}$ and Manal A. H. El-Gamal ${ }^{*}$ \\ Soils, Water and Environ. Res. Inst. Agric. Res. Center, Giza, Egypt. \\ ${ }^{* *}$ Botany Dept., Fac. of Science (Damietta), Mansoura Univ., Egypt.
}

\begin{abstract}
Five algal species forming blooms at North Delta-Egypt, collected from diverse locations, were screened for their efficiency as antibiotic activity against some plant pathogenic fungi. The algal extracts (aqueous and alcoholic) as well as culture filtrate of Spirulina maxima, Oscillatoria agardhii, Chlorella vulgaris, Ulva lactuca and Cladophora albida were tested against a representative group of fungi. Growth inhibition of the fungal species was detected on exposure to each treatment of the algal species. The results show that $O$. agardhii was the most potent alga with an average growth inhibition of about $49.0 \%$ over all treatments and all tested fungi. The most effective treatment for S. maxima, $O$. agardhii and $U$. lactuca was the culture filtrate; meanwhile, the ethanolic extract of both $C$. vulgaris and C. albida was the most pronounced treatment over all tested fungi. Complete inhibition was observed to Sclerotium rolfsii, Sclertinia sclerotiorum and Verticillium alboatrum on exposure to the culture filtrate of $O$. agardhii. The results are discussed in the light of the ability of these algae to produce bioactive secondary metabolites, secreted into the surrounded medium, which possess an inhibitory effect on the fungal growth.
\end{abstract}

\section{Introduction}

One of the main reasons for interest in allelopathy is that it could be one of the key factors that promote the dominance of marine and freshwater harmful algal bloom-forming species over other phytoplankton species (Legrand et al., 2003). Bioactive secondary metabolites of the massive algal blooms at North Delta-Egypt might provide novel useful and structurally specific compounds with biological activity. Investigations of antibiotic activity of marine algae have focused on the effect of algal extracts on bacteria, with relatively little attention paid to their potential activity against fungi (Tariq, 1991). Microalgae produce a wide array of compounds with biological activity. These include antibiotics, algicides, toxins, pharmaceutically active compounds and plant growth regulators (Skulberg, 2000) as well as compounds active against mammalian cell tissue (Carmichael, 1992). 
Blue green algae (cyanobacteria) have been recognized in the last decades as a source of novel cytotoxic and antifungal metabolites; some of these metabolites provide potential leads for the development of new pharmaceutical compounds (Frankmolle et al., 1992a).

Rice (1984) defined allelopathy as any direct or indirect harmful or beneficial effects of one plant, including microbes, on other plants in its vicinity through chemicals that escape into the environment. Allelopathic activity among phytoplankton eutrophied system is usually detected after examining the sequence of the dominant algal species in an algal bloom.

Nevertheless, Amer (2002) claimed that in some cases the allelopathic algicidal activity inferred from dual culture could result from shifting environmental conditions, such as $\mathrm{pH}$, and so appeared to be due to an allelopathic chemical. When these processes are better understood, microalgae might become economic sources of new drugs because production can be optimized in controlled culture.

Due to antifungal activity, Welch (1962) demonstrated that out of 35 marine algae, the red algae Laurencia obtusa and Wrangelia argus and the bluegreen alga Lyngbya majuscula were the most effective against the pathogenic fungi. Shelat (1981) found that methanolic extract of Gelidiella acerosa was most effective against Candida tropicalis and that of Gracilaria cortcata against Candida albicans. A broad-spectrum antifungal substance has been extracted from the culture medium of Fischerella ambigua (Ghasemi et al., 2004).

Caccamese et al. (1981) demonstrated that the lipid extracts of Cystoseria balearica (Phaeophyceae) and Codium effusum (Chlorophyceae) showed an inhibitory effect against Phoma tracheiphila fungus.

The blue- green alga Lyngbya majuscula has been found to produce two antifungal compounds (Moore and Entzeroth, 1988). De Cano et al. (1990) demonstrated antifungal activity of the terrestrial cyanobacterium Nostoc muscorum against Candida albicans to be accomplished by phenolic compounds.

Bonjouklian et al. (1991) found that indolo-(2, 3-a)carbazoles (tjipanazoles) of Tolypothrix tjipanasensis extracts are responsible for the moderate fungicidal activity against Candida albicans, Trichophyton mentagrophytes and Aspergillus flavus. Also, laxaphycins extracted from the blue - green alga Anabaena laxa, exhibited marked antifungal activity against Aspergillus oryzae, Candida albicans, Penicillium notatum, Saccharomyces cervisiae and Trichopyton mentagrophytes (Frankmolle et al., 1992b).

Konig and Wright (1997) suggested that the dichloromethane extract of the marine red alga Laurencia obtusa has antifungal activity especially towards Ustilago violacea. Both the aqueous and methanolic extracts of Lyngbya majuscula had antifungal activity against Aspergillus flavus, Dictyosporium cocophilum, Westerdykella dispersa in addition to some unknown species of Basidiomycetes, but Botrydiplodia theobromae was affected only by the methanolic extract (Zakaria et al., 2002). 
The aim of the present work is to test the harmful allelopathic effect of some algae known to form bloom at North Delta-Egypt against some plant pathogenic fungi namely, Alternaria alternata, Fusarium oxysporum, Cephalosporium maydis, Macrophomina phaseolina, Sclerotium rolfsii, Sclerotinia sclerotiorum, Rhizoctonia solani, Phoma sp. and Verticillium alboatrum.

\section{Materials and Methods}

The algal species namely Spirulina maxima, Oscillatoria agardhii, Chlorella vulgaris, Cladophora albida and Ulva lactuca are known to form blooms at North Delta-Egypt were chosen from their natural water habitat during their bloom occurrence to evaluate their harmful allelopathic effect against some plant pathogenic fungi.

Some of these algae were collected from their natural water habitat during their maximum growth period and used directly such as Chlorella vulgaris, Cladophora albida and Ulva lactuca. Fifty grams of the harvested algal materials were rinsed several times with tap water and then thoroughly washed with distilled water, to remove visible epiphytes and calcareous deposits and stored in freezer till extraction. In addition, the liquid left (culture filtrate) after algal harvesting was centrifuged to remove any insoluble materials and then sterilized by passing through filter membrane $(0.2 \mu \mathrm{m})$ and then tested for antifungal activity.

On the other hand, both collected Spirulina maxima and Oscillatoria agardhii were thoroughly washed and artificially cultured in the laboratory for propagation. This task was done because of their severely polluted water habitat; hence pure cultures are necessary to avoid interference of the pollutants with algal action. Propagation of both algal species was done using the recommended synthetic media, Zarrouk (1966) for the former and Allen and Stanier (1968) for the latter, both cultured algae were incubated on a rotary shaking incubator at 150 $\mathrm{rpm}$ under light intensity of $4000 \mathrm{lux}$ and temperature of $35^{\circ} \mathrm{C}$. The propagation was continued up to their appropriate $\log$ phase stage (21 days and 15 days, respectively). Algal biomass was then separated from the culture medium and tested individually against some plant pathogenic fungi; the culture filtrate for each alga was also tested against the chosen plant pathogenic fungi.

\section{Representative plant pathogenic fungi, their propagation and maintenance:}

The plant pathogenic fungi namely, Alternaria alternata, Fusarium oxysporum, Cephalosporium maydis, Macrophomina phaseolina, Sclerotium rolfsii, Sclerotinia sclerotiorum, Rhizoctonia solani, Phoma sp. and Verticillium alboatrum were kindly supplied with the Plant Diseases Research Institute, Agricultural Research Center, Giza, Egypt, and used for experimentation during the present investigation. 
Cezpaek's Dox medium (Stevens, 1981) was used to propagate and maintain these selected fungi. Fungi were inoculated on solidified Dox medium for 7-14 days at $28^{\circ} \mathrm{C}$. Cultures were then kept in a refrigerator at $4{ }^{\circ} \mathrm{C}$ and were occasionally sub cultured every two months on the same medium.

\section{Algal secondary metabolites extraction:}

The aqueous extract was prepared by homogenizing $50 \mathrm{~g}$ of the frozen algal tissues in $50 \mathrm{~mL}$ distilled water for 20 min., followed by centrifugation at 4,000 rpm. The formed pellets were reextracted in $50 \mathrm{~mL}$ distilled water. Both formed supernatants were mixed together and kept at $4^{\circ} \mathrm{C}$ till work up. The ethanolic extract of algal tissues was prepared following the same procedure as in aqueous extraction, except that of $80 \%$ ethanol was used as a solvent instead of distilled water. The supernatant was evaporated to dryness under vacuum at $40{ }^{\circ} \mathrm{C}$ and the residue was then dissolved in $50 \mathrm{~mL}$ of a mixture of polyethylene- glycol (PEG) 400 and physiological Tris-buffer ( $\mathrm{pH} 7.4$ ) at aratio of 4:6, respectively, and then subjected for testing their antifungal activity according to the procedure described by Tariq (1991).

\section{Allelopathic assay technique:}

The dilution plate method described by Tariq (1991) was used to assess the antibiotic activities of algal extracts and culture filtrate against the aforementioned pathogenic fungi. Aliquots $(1 \mathrm{~mL})$ of the algal extract or culture filtrate, or Tris / PEG (as control) were mixed with $9 \mathrm{~mL}$ aliquots of Dox medium and poured into Petri dishes. Each dish was inoculated with a fungus mycelial disc (1.4 cm diameter) from the edge of 7-10 days-old culture of the tested fungus that was previously grown on Dox medium. Three dishes were used for each treatment and the mean radial extension of each culture was determined at regular time intervals, till the growth of each fungus has completely covered all the plate surface of the control treatment, after which the experiment has to be ceased.

All obtained data were statistically analyzed using the Least Significant Difference Comparison between means at the probability of 5\% as described by Gomez and Gomez (1984).

\section{Results and Discussion}

\section{Spirulina maxima Geitler:}

Data in Table (1) present the biocontrol activity of Spirulina maxima against some pathogenic fungi. The various treatments of S. maxima led to significant reduction in growth of all the tested fungi, except for Rhizoctonia solani when treated with aqueous extract, where fungal growth exhibited a normal growth behavior. 
Table (1): Antifungal activity of Spirulina maxima against different species of pathogenic fungi.

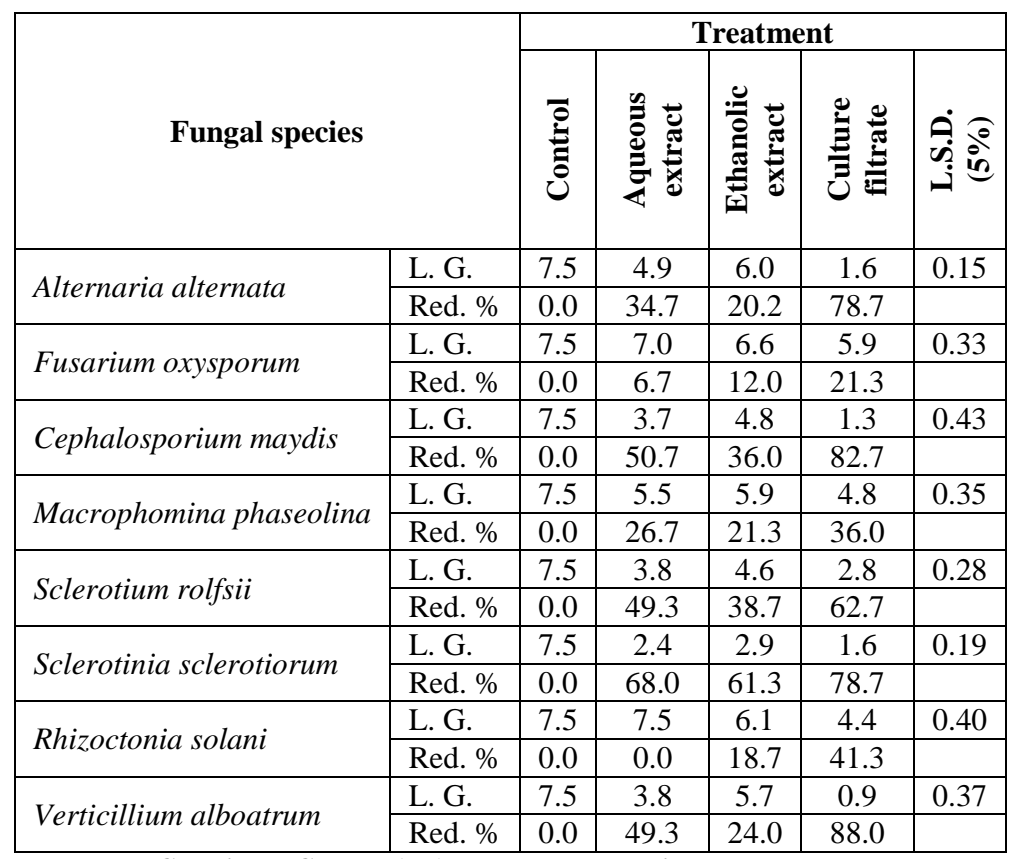

L.G.= Linear Growth (cm); Red. \%= Reduction percentage

Among the various algal treatments used, algal culture filtrate recorded the most drastic effect on the fugal growth (61.2\% average reduction), followed by the aqueous extract (35.7\% average reduction), and the ethanolic extract was the least effective treatment $(29.0 \%$ average reduction) due to the tested fungi.

The effect of various treatments on the tested fungi growth was differed according to the fungal species. The highest effect of the aqueous extract treatment was attained against the growth of Sclerotinia sclerotiorum $(68.0 \%$ reduction), compared to other fungi. While, $R$. solani was the only fungal species, which had not affected by the exposure to this treatment.

Likewise, the ethanolic extract was more effective against $S$. sclerotiorum in reducing its growth by $61.3 \%$, compared to the other tested fungi.

Due to the most adverse effect of the culture filtrate against the tested fungi, Verticillium alboatrum and Cephalosporium maydis showed the lowest growth in response to this treatment ( $88.0 \%$ and $82.7 \%$ reduction), respectively.

In conclusion, the present data reveal that the most effective antifungal agent against the tested fungi was the culture filtrate of $S$. maxima. The broad activity might point out to the ability of the alga to produce bioactive secondary metabolites, secreted into the surrounded medium. These bioactive substances seem to hinder the growth of tested fungi with different extents. S. maxima, like the other Cyanophytes has the ability to produce a variety of lethal toxins. These 
results are in accordance with Hayashi et al. (1996) who found that a natural sulfated polysaccaride, calcium spirulan, produced by $S$. platensis, had an antiviral effect. In this respect, Ozdemir et al. (2004) found that volatile components and various extracts of $S$. platensis had potent antimicrobial activities against several strains of both Gram-positive and Gram-negative bacteria and Candida albicans.

\section{Oscillatoria agardhii Gomont:}

All treatments of Oscillatoria agardhii (Table 2) exhibited positive significant effects against the growth of the tested fungal species, except for both Fusarium oxysporum and Phoma sp. when treated with any of aqueous and ethanolic extracts.

Among the different treatments used, culture filtrate was the most potent in reducing fungal growth ( $86.6 \%$ average reduction), followed by aqueous extract (39.2\% average reduction) and then ethanolic extract $(22.7 \%$ average reduction). Aqueous extract was more active against S. sclerotiorum (93.30\% growth reduction). While, Macrophomina phaseolina was the most affected fungus among the tested organisms due to the effect of ethanolic extract (50.1\% growth reduction). Culture filtrate led to complete inhibition (no growth) in Sclerotium rolfsii, S. sclerotiorum and $V$. alboatrum, while, the growth of Alternaria alternata, C. maydis, M. phaseolina and Phoma. sp. were reduced by 90.1, 98.7, and $89.3 \%$.

The present results pointed out to a strong drastic effect of culture filtrate of $O$. agardhii against all the tested fungi, leading to complete inhibition of some fungi, surpassing the effect of both aqueous and ethanolic extracts. This broad activity of culture filtrate might be reflecting the presence of bioactive substances produced by the alga and secreted into the bathing medium. These results are concured with those obtained by (Carmichael, 1992 and Brittain et al., 2000) who found that Oscillatoria, a member of cyanobacteria, is capable of producing lethal neurotoxins and hepatotoxins. Moreover, Marwah et al. (1995) found that the effect of culture filtrate of the alga Oscillatoria sp. was in duplicate and resulted in growth inhibition of the tested organisms. These findings are coincided with the current data, which, revealed that the Oscillatoria culture filtrate had the greatest antifungal effect.

While, Mudassir (1995) found that ethanolic extracts of Chara vulgaris, Cladophora fracta and Oscillatoria subbrevis exhibited strong antifungal activity against ten fungal strains. Oxygenated fatty acids (Coriolic and $\alpha$-dimorphecolic acids) have been isolated from Oscillatoria redekei. These compounds possess antifungal activity against the rice blast fungus Pricularia oryzae (Kato et al., 1993). 
Table (2): Antifungal activity of Oscillatoria agardhii against different species of pathogenic fungi.

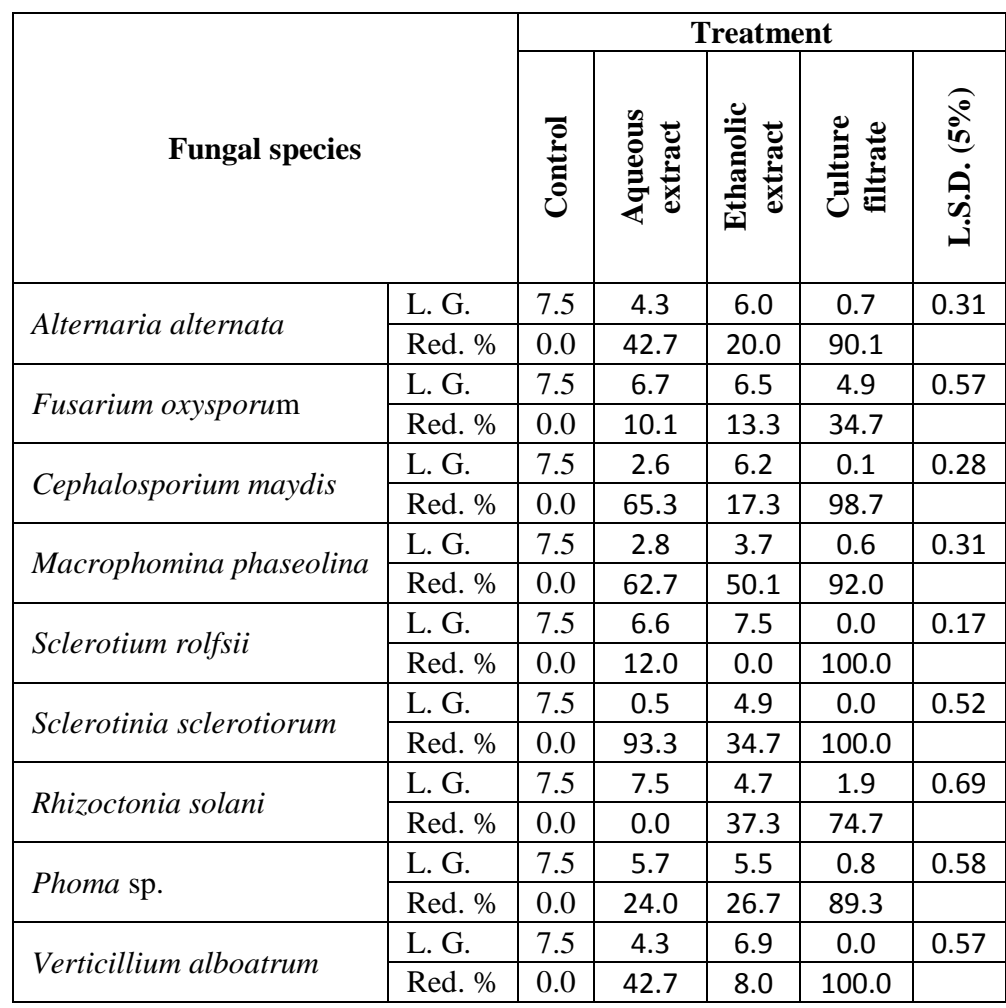

L.G.= Linear Growth (cm); Red. \%= Reduction percentage

\section{Chlorella vulgaris Beijerinck:}

All $C$. vulgaris treatments (Table 3) led to significant decrease in the linear growth of the testing fungi except for $F$. oxysprum, $M$. phaseolina and $R$. solani when treated with both aqueous extract and culture filtrate, and $V$. alboatrum when treated with aqueous extract only.

Among the three treatments used, ethanolic extract was the most effective leading to an average growth inhibition of about $66.4 \%$ below the control, followed by culture filtrate and aqueous extract, which led to comparable growth reduction of about 18.36 and $16.6 \%$, respectively.

Nevertheless, the most severe inhibition effect of aqueous extract was against $C$. maydis $(61.3 \%$ below the control). While, a strong drastic effect of ethanolic extract was recorded against $R$. solani, leading to complete growth inhibition. S. rolfsii was the most affected fungus among the tested organisms due to the effect of culture filtrate (61.3\% growth reduction).

The present results suggest that, among the three investigated treatments, ethanolic extract was the most effective against the tested fungi compared to the 
aqueous extract and the culture filtrate. However, the inhibitory effect due to the ethanolic extract of $C$. vulgaris may be explained by that $C$. vulgaris produce active substances, soluble in alcohol but insoluble in water, which, lead to selective inhibition of the growth of the tested fungi. These findings are concured with Pratt et al. (1944) who demonstrated that chlorellin, a mixture of fatty acids with antibacterial activity accumulated in the culture of Chlorella. Ostensvik et al. (1998) and Skulberg (2000) who revealed that methanolic extract of natural blooms of microalgae possessed more pronounced growth inhibition against several strains of bacteria than the aqueous extract. More recently, Abdel-Baky et al. (2002) isolated volatile metabolites from the green microalga, C. vulgaris, which had a strong phytotoxic effect. In addition, Matusiak and Krzywicka (1975) reported that an ethanolic extract from the terrestrial Chlorophyte, Chlorella vulgaris Beij. inhibited the growth of Aspergillus oryzae.

Table (3): Antifungal activity of Chlorella vulgaris against different species of pathogenic fungi.

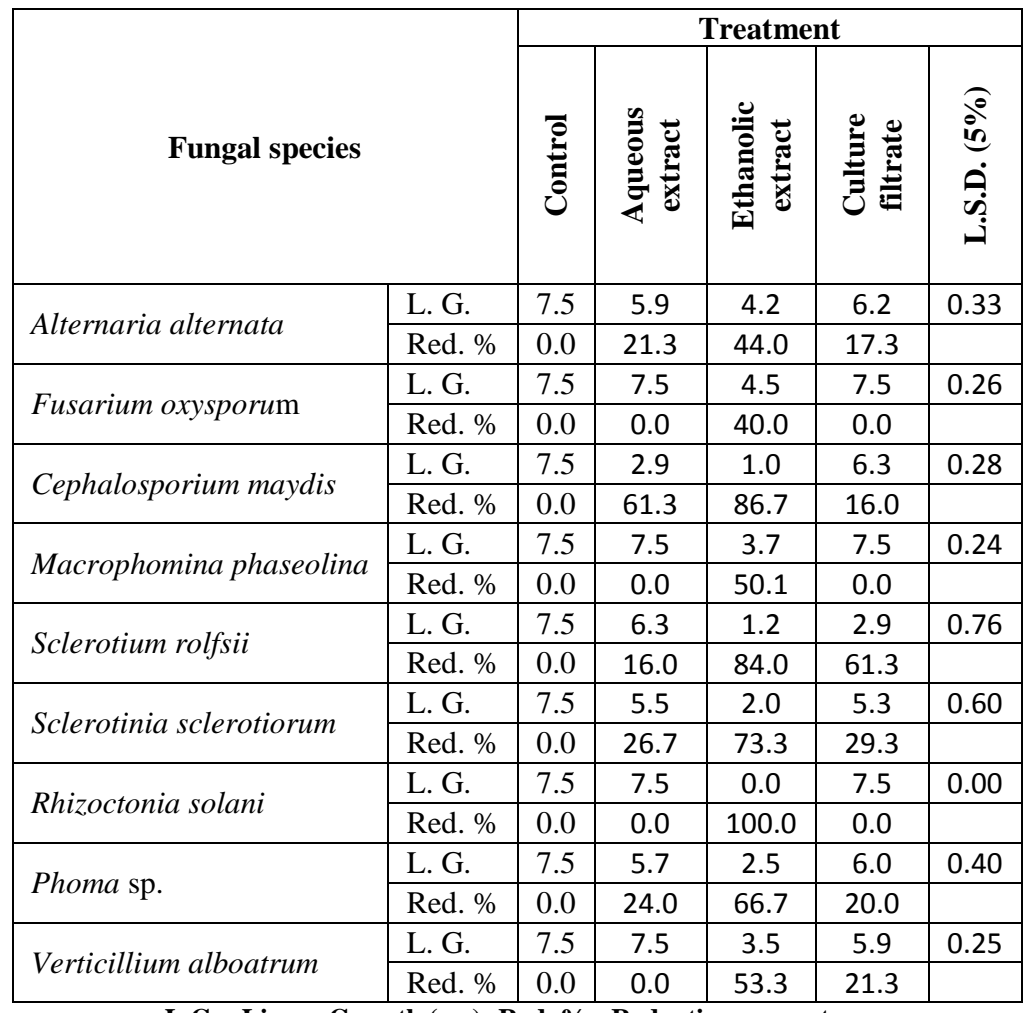

L.G.= Linear Growth (cm); Red. \%= Reduction percentage

\section{Cladophora albida (Hudson) Kützing:}

The different treatments of Cladophora albida (Table 4) exhibited more or less comparable antifungal activity. Nevertheless, ethanolic extract was the 
most effective with an average inhibitory effect of about $33.0 \%$ growth reduction below the control, followed by aqueous extract and culture filtrate with an average growth reduction of about 25.2 and $22.8 \%$ below the control, respectively.

Table (4): Antifungal activity of Cladophora albida against different species of pathogenic fungi.

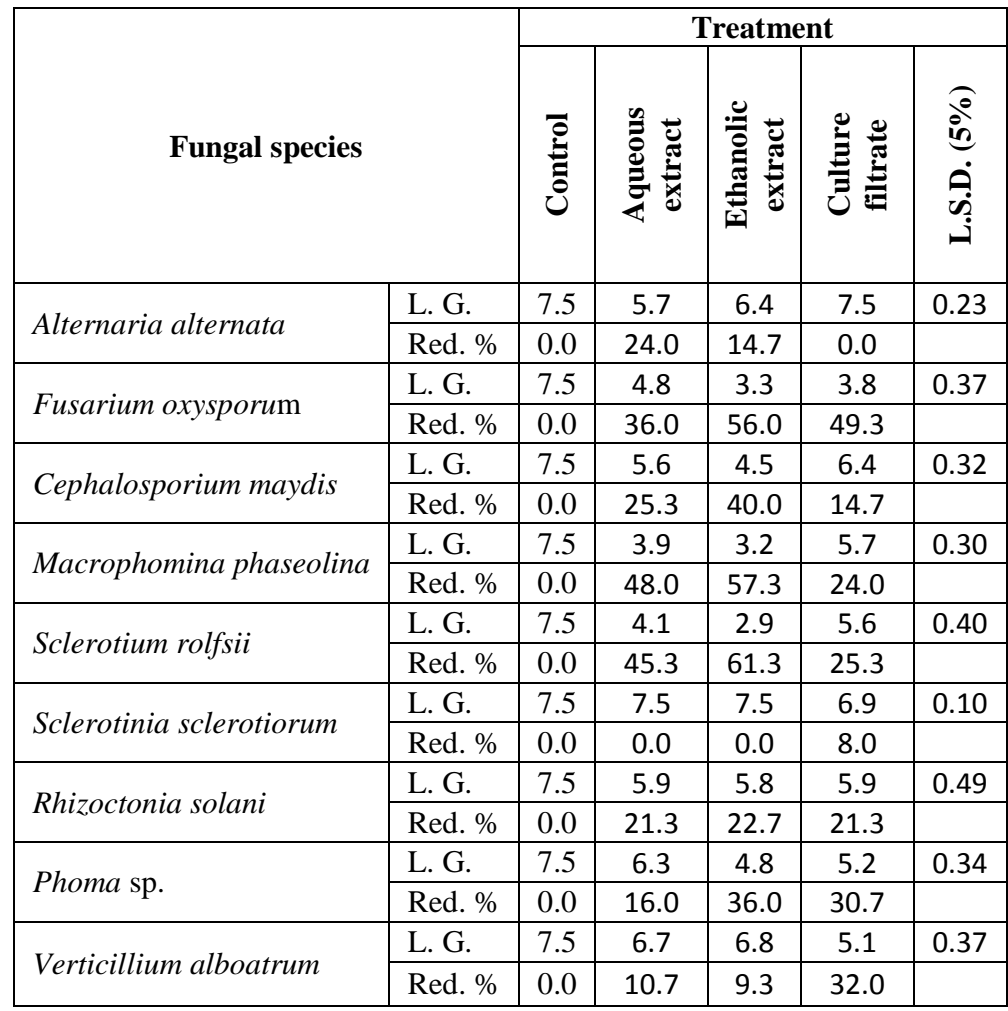

L.G.= Linear Growth $(\mathrm{cm})$; Red. \% $=$ Reduction percentage

With respect to the response of individual fungi to the different treatments, $M$. phaseolina, $F$. oxysporum and $S$. rolfsii were subjected to the most drastic inhibition in growth (48.0, 49.3 and $61.3 \%$, respectively) under the impact of aqueous, ethanolic extracts and culture filtrate, respectively. By contrast, the least affected fungus was S. sclerotiorum, with mild growth inhibition $8.0 \%$ only under the effect of culture filtrate and no growth reductions $(0.0 \%)$ under the effect of aqueous and ethanolic extracts.

The marked effectiveness of ethanolic extract against the tested fungi may due to the ability of the organic solvent to extract the bioactive substances produced by the macroalga Cladophora albida. This result is in accordance with those obtained by Mudassir (1995) who found that ethanolic extracts of Chara 
vulgaris, Cladophora fracta and Oscillatoria subbrevis exhibited strong antifungal activity against ten fungal strains.

Recently, Kamenarska et al. (2004) found that the chloroform-n-butanol extract and the volatiles isolated from Cladophora rivularis (L.) Hoek, were found to possess marked activity against the Gram - positive Staphylococcus aureus with no activity neither against the Gram - negative Escherichia coli nor the fungus Candida albicans.

\section{Ulva lactuca Linnaéus:}

The three tested treatments of $U$. lactuca (Table 5) had significant positive effects against the different tested fungi and that culture filtrate was the most effective, leading to an average growth inhibition of $38.70 \%$, followed by aqueous extract (33.2\% growth reduction) and then ethanolic extract (17.9\% reduction).

Table (5): Antifungal activity of Ulva lactuca against different species of pathogenic fungi.

\begin{tabular}{|c|c|c|c|c|c|c|}
\hline \multicolumn{7}{|c|}{ tment } \\
\hline \multicolumn{2}{|l|}{ Fungal species } & $\stackrel{\bar{\Xi}}{E}$ & $\stackrel{\mathscr{E}}{\bar{E}}$ & 冚 & $\stackrel{\Xi}{\Xi}$ & $\begin{array}{l}\frac{8}{8} \\
\text { in }\end{array}$ \\
\hline \multirow{2}{*}{ Alternaria alternata } & L. G. & 7.5 & 4.9 & 6.8 & 3.2 & 0.34 \\
\hline & Red. $\%$ & 0.0 & 34.7 & 9.3 & 57.3 & \\
\hline \multirow{2}{*}{ Fusarium oxysporum } & L. G. & 7.5 & 1.5 & 6.8 & 3.6 & 0.23 \\
\hline & Red. $\%$ & 0.0 & 80.0 & 9.3 & 52.0 & \\
\hline \multirow{2}{*}{ Cephalosporium maydis } & L. G. & 7.5 & 6.8 & 6.7 & 6.6 & 0.47 \\
\hline & Red. $\%$ & 0.0 & 9.3 & 10.7 & 12.0 & \\
\hline \multirow{2}{*}{ Macrophomina phaseolina } & L. G. & 7.5 & 7.0 & 5.1 & 2.9 & 0.40 \\
\hline & Red. $\%$ & 0.0 & 6.7 & 32.0 & 61.3 & \\
\hline \multirow{2}{*}{ Sclerotium rolfsii } & L. G. & 7.5 & 4.5 & 1.2 & 1.1 & 0.31 \\
\hline & Red. $\%$ & 0.0 & 40.0 & 84.0 & 85.3 & \\
\hline \multirow{2}{*}{ Sclerotinia sclerotiorum } & L. G. & 7.5 & 7.5 & 7.5 & 7.5 & 0.00 \\
\hline & Red. $\%$ & 0.0 & 0.0 & 0.0 & 0.0 & \\
\hline \multirow{2}{*}{ Rhizoctonia solani } & L. G. & 7.5 & 7.5 & 7.5 & 7.5 & 0.00 \\
\hline & Red. $\%$ & 0.0 & 0.0 & 0.0 & 0.0 & \\
\hline \multirow{2}{*}{ Phoma sp. } & L. G. & 7.5 & 0.7 & 6.3 & 5.6 & 0.40 \\
\hline & Red. $\%$ & 0.0 & 90.7 & 16.0 & 25.3 & \\
\hline \multirow{2}{*}{ Verticillium alboatrum } & L. G. & 7.5 & 4.70 & 7.50 & 3.40 & 0.20 \\
\hline & Red. $\%$ & 0.0 & 37.3 & 0.0 & 54.7 & \\
\hline
\end{tabular}

L.G.= Linear Growth $(\mathrm{cm}) ;$ Red. \% = Reduction percentage

Growth of Phoma sp. and S. rolfsii were subjected to the maximum inhibition under the effect of aqueous, ethanolic extracts and culture filtrate treatments. While, S.sclerotiorum and R. solani were the only fungal species, which had not affected by the exposure to all algal tested treatments, both species 
recorded $0.0 \%$ growth inhibition with both aqueous ethanolic extracts and culture filtrate.

In conclusion, the obtained results indicated that $U$. lactuca can act as a potential source for the bioactive compounds against some pathogenic fungi. Marine macroalgae are well - documented to possess antibacterial and antifungal activities (Vlachos et al., 1996).

Based on fungal response to the different treatments, it can be concluded that the same fungus may respond differentially to the different extracts of the same algal species. Tariq (1991) suggested that different substances in the same seaweed might cause the algal inhibitory effect against the tested fungi.

In agreement with the present results, Lima-Filhol et al. (2002) found that water extract of Ulva fasciata was effective against Proteus vulgaris, but organic solvent extract was not.

Kumar and Rengasamy (2000) observed that Ulva lactuca was one of eleven seaweeds that had antibacterial activity against the plant pathogenic bacterium, Xanthomonas oryzae pv. Oryzae. Also, Awad (2000) reported that Ulva lactuca contains steroid compounds, which have antimicrobial activity against various microorganisms.

Recently, Cluzet et al. (2004) found that prior treatment of Medicago truncatula with Ulva extract protected the plants against subsequent infection by the pathogenic fungus Colletotrichum trifolii.

In conclusion, the algal species tested in this study against some plant pathogenic fungi revealed the potential effect in affecting the growth of these fungi. The priority was for the culture filtrate of Oscillatoria agaredhii against all the tested fungi (86.6\% reduction in the growth). Moreover, this treatment has completely adverse the growth of $S$. rolfsii, S. sclerotiorum and V. alboatrum (100 $\%$ growth reduction).

\section{References}

Abdel-Baky, H. H.; Shallan, M. A.; El-Baroty, G. and El-Baz, F. K. (2002). Volatile compounds of the microalga Chlorella vulgaris and their phytotoxic effect. Pakistan J. Biol. Sci., 5:61-65.

Allen, M. M. and Stanier, R. Y. (1968). Selective isolation of blue-green algae from Water and Soil. J. Gen. Microbiol., 51:203-209.

Amer, M. S. (2002). Antibiotic production by some species of blue-green algae (Cyanobacteria). M. Sc. thesis, Tanta Univ., Egypt, pp.121

Awad, N. E. (2000). Biologically active steroid from the green alga Ulva lactuca. Phytotherapy Res., 14:641-643.

Bonjouklian, R.; Smitka, T. A.; Doolin, L. E.; Molloy, R. M.; Debono, M.; Shaffer, S. A.; Moore, R. E.; Stewart, J. B. and Patterson, G. M. L. (1991). Tjipanazoles, new antifungal agents from the blue-green alga Tolypothrix tjipanasensis. Tetrahedron, 47:7739-7750. 
Brittain, S.; Mohamed, Z. A.; Wang, J.; Lehmann, V. K. B.; Carmicheal, W. W. and Rinehart, K. L. (2000). Isolation and characterization of microcystins from a River Nile strain of Oscillatoria tenuis Agardh ex Gomont. Toxicon, 38:1759-1771.

Caccamese, S.; Azzolina, R.; Furnari, G.; Cormaci, M. and Grasso, S. (1981). Antimicrobial and antiviral activities of some marine algae from eastern Sicily. Bot. Mar., 24:365-367.

Carmichael, W. W. (1992). Cyanobacteria secondary metabolites-the cyanotoxins. J. Appl. Bacteriol., 72:445-459.

Cluzet, S.; Torregrosa, C.; Jacquet, C.; Lafitte, C.; Fournier, J.; Mercier, L.; Salamagne, S.; Briand, X.; Esquerre-Yugaye, M. T. and Dumas, B. (2004). Gene expression profiling and protection of Medicago truncatula against a fungal infection in response to an elicitor from green algae Ulva spp. Plant Cell and Environ., 27:917-928.

De Cano, M. M. S.; De Mule, M. C. Z.; De Caire, C. Z. and De Halperin, D. R. (1990). Inhibition of Candida albicans and Staphylococcus aureus by phenolic compounds from the terrestrial cyanobacterium Nostoc muscorum. J. Appl. Phycol., 1:79-82.

Frankmolle, W. P.; Knubel, G.; Moore, R. E. and Patterson, G. M. L. (1992a). Antifungal cyclic peptides from the terrestrial blue-green alga Anabeana laxa. II. Structure of laxaphycins A, B, D and E. J. Antibiotic, 45:1458-1466.

Frankmolle, W. P.; Larsen, L. K.; Caplan, F. R.; Patterson, G. M. L.; Knubel, G.; Levine, I. A. and Moore, R. E. (1992b). Antifungal cyclic peptides from the terrestial blue-green alga Anabeana laxa. I. Isolation and biological properties. J. Antibiotic, 45:1451-1457.

Ghasemi, Y.; Yazdi, M. T.; Shafiee, A.; Amini, M; Shadman, S. and Zarrini, G. (2004). Parsigguine, a novel antimicrobial substance from Fischerella ambigua. Pharmaceutical Biology, 42:318-322.

Gomez, K. A. and Gomez, A. A. (1984). Statistical procedures for Agricultural research, $\left(2^{\text {nd }}\right.$ ed), International Rice Res. Inst. publications. Los Banos, Manila, Philippines. pp. 20-29 and 359-387.

Hayashi, T.; Hayashi, K.; Maeda, M. and Kojima, I. (1996). Calcium spirulan, an inhibitor of enveloped virus replication, from a blue-green alga Spirulina platensis. J. Natural Products, 59:83-87.

Kamenarska, Z.; Stefanov, K.; Konaklieva, S. D.; Najdenski, H.; Tsvetkova, I. and Popov, S. (2004). Chemical composition and biological activity of the brackish water green alga Cladophora rivularis (L.) Hoek. Bot. Mar., 47:215-221.

Kato, T.; Yamaguchi, Y.; Namai, T. and Hirukawa, T. (1993). Oxygenated fatty acids with anti-rice blast fungus activity in rice plants. Biosci. Biotechnol. Biochem., 57:283-287. 
Konig, M. G. and Wright, D. A. (1997). Sesquiterpene content of the antibacterial dichloromethane extract of the marine red alga Laurencia obtusa. Planta Med., 63:168-187.

Kumar, K. A. and Rengasamy, R. (2000). Evaluation of antibacterial potential of seaweeds occurring along the coast of Tamil Nadu, India against the plant pathogenic bacterium Xanthomonas oryzae pv. Oryzae (Ishiyama) dye. Bot. Mar., 43:409-415.

Legrand, C.; Renefors, K.; Fistarol, G. O. and Graneli, E. (2003). Allelopathy in phytoplankton-biochemical, ecological and evolutionary aspects. Phycologia, 42:406-419.

Lima-Filhol, J. V. M.; Carvalho, A. F. F. U.; Freitas, S. M. and Melo, V. M. M. (2002). Antimicrobial activity of extracts of six macroalgae from the Northeastern Brazilian coast. Braz. J. Microbiol., 33(4):311-314.

Marwah, J. B.; Shakila, T.M.; Rao, N. S. and Bagchi, S. N. (1995). Detoxification of a local Microcystis bloom by an algicidal antibiotic from Oscillatoria late-virens. Indian J. Exp. Biol., 33:97-100.

Matusiak, K. and Krzywicka, A. (1975). Influence of the extract of Chlorella vulgaris on growth of fungi. Acta Microbiol. Polon Ser. B, 51-54.

Moore, R. E. and Entzeroth, M. (1988). Majusculamide D and deoxymajsculamide D, two cytotoxins from Lyngbya majuscula. Phytochem., 27:3101.

Mudassir, I. (1995). Biochemical studies of algae from inland waters of Balochistan. Ph. D. thesis, Balochistan, Quetta Univ., Pakistan.

Ostensvik, O.; Skulberg, O. M.; Underdal, B. and Hormazabal, V. (1998). Antibacterial properties of extracts from selected planktonic freshwater Cyanobacteria a comparative study of bacterial bioassays. J. Appl. Microbiol., 84:117-1124.

Ozdemir, G.; Karabay, N. U.; Dalay, M. C.; Pazarbasi, B. (2004). Antibacterial activity of volatile components and various extracts of Spiurulina platensis. Phytotherapy Res., 18:754-757.

Pratt, R.; Daniels, T. C.; Eiler, J. J.; Gunnison, J. B.; Kumler, W. D.; Oneto, J. F. and Strait, L. A. (1944). Chlorellin, an antibacterial substance from Chlorella. Science, 99:351-352.

Rice, E. L. (1984). Allelopathy. Academic Press, Orlando, Florida.

Shelat, Y. A. (1981). Screening of Rhodophyceae for antifungal activity. $J$. Geobios (Jodhpur), 8:51-54.

Skulberg, O. M. (2000). Microalgae as a source of bioactive moleculesexperience from Cyanophyta research. J. Appl. Phycol., 12:341-348.

Stevens, R. B. (1981). In: Mycology guidebook. Mycological Society of America, Univ. of Washington Press, USA. pp. 683.

Tariq, V. N. (1991). Antifungal activity in crude extracts of marine red algae. Mycol. Res., 95:1433-1440. 
Vlachos, V.; Critchley, A. T. and Von Holy, A. (1996). Establishment of a protocol for testing antimicrobial activity in southern African macroalgae. Microbios, 88:115-123.

Welch, A. M. (1962). Preliminary survey of fungistatic properties of marine algae. J. Bacteriol., 83:97-99.

Zakaria, A. M.; Abdel-Wahab, M. A. and El-Sharouny, H. M. (2002). Antimicrobial activity of Egyptian marine cyanobacterium Lyngbya majuscula gomont. Egypt. J. Phycol., 3:84-90.

Zarrouk, C. (1966). Contribution á l'étude d'une cyanophycée. Influence de divers facteurs physiques et chimiques sur la croissance et la photosynthése de Spirulina maxima (Setch. Et Gardner) Geitler. Ph. D.Thesis. University of Paris, France.

\section{النشاط الأليلوباثيك لتجمعات الطحالب ضد بعض الفطريات الممرضة للنبات

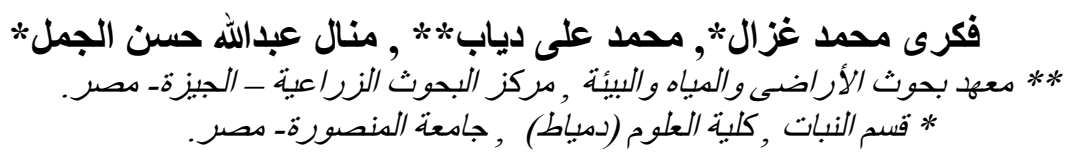

لإختبار قدرة الطحالب على إنتاج مو اد حيوية مضادة لنمو بعض الفطريات الممرضة للنبات فإنه

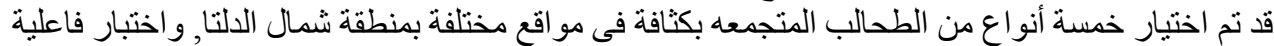

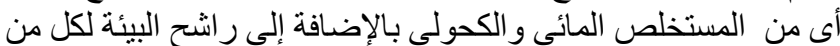

Spirulina maxima, Oscillatoria agardhii, Chlorella vulgaris, Ulva lactuca and Cladophora albida

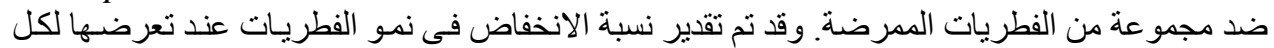

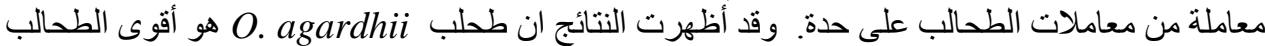

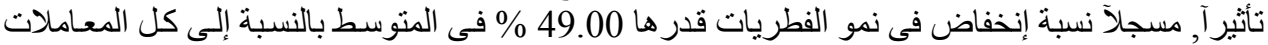

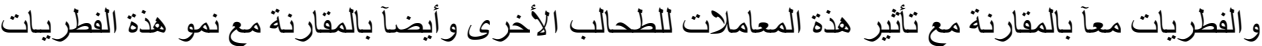

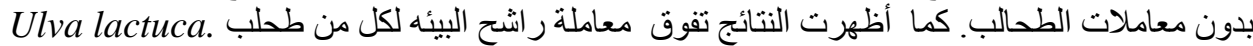

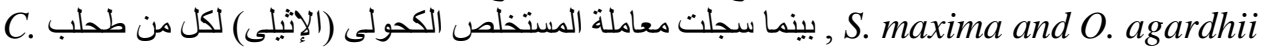
C. albida and vulgaris

Sclerotiom rolfsii, Sclertinia sclerotiorum and Verticillium alboatrum

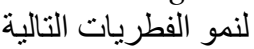

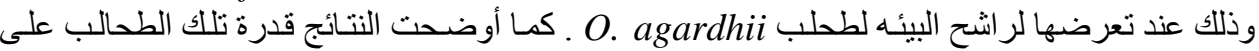
إفراز نو اتج ثانوية نثطة يمكنها تثيط نمو تلك الفئل الفريات. 